\title{
INFLUÊNCIA ECOLÓGICA NO DESENVOLVIMENTO DO FRUTO E NO TEOR DE ÓLEO NA POLPA DO ABACATE (Persea americana MILLER)*
}

\author{
ANTONIO A. LUCCHESI ** \\ HEITOR W.S. MONTENEGRO ***
}

\section{RESUMO}

Conduziu-se, um experimento para verificar a evolução do teor de óleo na poipa do abacate, em três regiões ecologicamente diferentes do Estado de São Paulo (Novo Horizonte, Limeira e Itapetininga), com a finalidade de se determinar o estágio adequado de colheita dos frutos para um maior rendimento industrial na produção de óleo.

Em cada região, utilizou-se três pomares e em cada pomar selecionou-se cinco árvores das cultivares 'Wagner', 'Prince' e 'Collinson', colhendo-se dois frutos de cada árvore, que no conjunto (dez frutos) formaram a amostra a ser analisada, para cada cultivar.

Efetuaram-se colheitas em épocas predeterminadas, visando a análise do desenvolvimento do fruto, desde a sua formação até a época de maturação. Efetuou-se também análises em amostras deixadas amadurecer até o ponto de consumo (polpa mole).

Através dos estudos realizados, verificou-se que o clima da região exerce influência no ciclo de frutificação (do florescimento à maturação) do abacate. Relacionando-se as regiões estudadas, em uma determinada data, os frutos se apresentavam em diferentes graus de desenvolvimento fisiológico, mais adiantados na região mais quente e mais atrasados na regiăo mais fria.

No estágio final de maturação do abacate, constatou-se uma influência do clima sobre o teor de óleo na polpa. Considera-se que o fator climático a influenciar o teor de óleo foi provavelmente a temperatura, determinando teores mais elevados na região mais fria.

Foi observado que a evoluçâo do teor de óleo na polpa do abacate se processa lentamente no início, acentuando-se no final do desenvolvimento do fruto. Constatou-se aumento no teor de óleo na polpa, enquanto o abacate permaneceu na árvore.

Não foi constatado influência das características do solo, dos tratos culturais e da idade dos pomares sobre o teor de óleo na polpa do abacate.

\section{INTRODUÇÃO}

A cultura do abacateiro, Persea americana Miller, recebeu nesses últimos anos notável incremento.

* Entregue para publicação em 3/12/1975. Parte da Tese apresentada pelo primeiro autor para a obtenção do título de Doutor na ESALQ/USP.

* Departamento de Botânica - ESALQ/USP.

*** Departamento de Agricultura e Horticultura - ESALQ/USP. 
Isto se deve primeiramente, à maior demanda do abacate como fruta fresca e em segundo lugar pelas perspectivas do seu aproveitamento industrial. Neste último aspecto, vasto campo está se abrindo para esta fruta. Além disso, devido a possibilidade da utilização de incentivos governamentais, o plantio de grandes áreas com abacateiros tem aumentado progressivamente.

Raríssimas investigações podem atualmente proporcionar dados necessários aos interessados na agro-indústria abacatícola. Os poucos ensaios realizados sempre objetivaram a produção de fruta para o consumo "in natura".

Segundo MONTENEGRO (1973), apesar do extraordinário valor alimentício do abacate, superior à laranja, maçã, pêra, uva, banana, e muitas outras frutas ainda não aỉ cançou entre nós, por lamentável desconhecimento, a posição de destaque que com justiça lhe cabe no meio frutícola.

A produção mundial de abacate, segundo MONTENEGRO (1973), é estimada em 500 a 600 mil toneladas, sendo seus principais produtores: Brasil (180.000), México (150.000), Estados Unidos (80.000), Filipinas (10.000), África do Sul, Cuba, Israel e Porto Rico, com 5.000 toneladas cada. No Brasil o principal estado produtor é São Paulo, com cerca de 80.000 toneladas, seguido de Minas Gerais e Rio de Janeiro.

Segundo o mesmo autor, considera-se a produção mundial de óleo de abacate ao redor de 120 toneladas, sendo que os principais países produtores são: Estados Unidos (40 a 60), Filipinas (10), África do Sul (9 a 10), Cuba (5 a 8), Camerum (5 a 10), México $(5$ a 7$)$ e França ( 1 a 2). O Brasil também extrai quantidades variáveis de óleo, havendo duas empresas extratoras em São Paulo, com vistas ao abastecimento de indústrias de cosméticos, nacionais e internacionais.

O óleo é utilizado comercialmente na indústria de cosméticos, devido ao seu extraordinário valor na conservação e restauração da pele, além das inúmeras utilizações em medicina.

O óleo extraído da polpa do abacate é bastante apreciado pelos cosmetólogos e farmacêuticos, devido ao fato dele reduzir a tensão superficial dos líquidos e de formar emulsões muito finas, além de ter enorme poder de penetração, que pode ser comparado à lanolina, não sendo irritante e possuindo altas quantidades de vitaminas lipossolúveis, fitoesterol e lecitina. Ademais, seu odor é suave, e rancifica muito pouco (HAENDLER, 1965 ; PAQUOT \& TASSEL, 1966; PANERAI, 1968 e HAENDLER, 1970).

Segundo DUPAIGNE (1970), a fração insaponificável do óleo de abacate possui a propriedade de curar certas afeç̧ões benignas ou graves, que resistem a vários tratamentos, tem a propriedade de restabelecer o tônus geral de indivíduos de idade avançada, funcionando portanto como um medicamento antifadiga.

Em cosmetologia, o óleo de abacate vem sendo largamente empregado no tratamento de descamações a pele e segundo THIERS (1971), seu efeito é comprovadamente positivo, quando usado só ou apenas sua fração insaponificável.

POPENOE (1924) cita que o óleo de abacate tem um coeficiente de digestibilidade (95\%), similar ao da gordura do leite. Por esse motivo o óleo de abacate tem sido recomendado como substituto do óleo de oliva na alimentação humana (LOVE, 1944).

Nos Estados Uridos, quando os pomares são danificados por geada e os frutos se 
tornam impróprios para o consumo, toda a colheita é destinada à extração do óleo (MONTENEGRO, 1960).

No Chile, pela sua importância entre as frutas e pelas suas reais possibilidades de industrialização, o abacateiro ocupa vastas áreas em zonas agrícolas, em solos dos mais caros do país (CORTES et alii, 1971).

SADIR (1972) cita que no Brasil, dos resíduos da extração do óleo do abacate, quando desidratados, obtém-se bom alimento para bovinos.

O conhecimento cada vez maior de suas utilizações e de seu valor comercial, vem provocando anualmente uma maior procura e consumo do óleo de abacate.

$O$ presente trabalho visa estudar as possíveis infiuências dos fatores ecológicos no teor de óleo do abacate.

\section{REVISÃo DA LITERATURA}

Sabe-se que o habitat natural de uma planta, através de sua ecologia, determina características normais relativas ao seu desenvolvimento e frutificação. Levadas para outro ambiente, essas características podem ser modificadas.

Assim, já foi comprevado em fruticultura, a influência de certos fatores climáticos e edáficos na modificação de certas características das plantas, tais como: porte, época de maturação e características qualitativas e quantitativas dos frutos (ULRICH, 1952; MONTENEGRO, 1958).

Segundo BIALE (1941); PRATT \& BIALE (1944) e BIALE \& YOUNG (1962), trabalhando com a cultivar 'Fuerte' na Califórnia, U.S.A., verificaram que o abaixamento da temperatura diminui o processo respiratório, aumentando dessa maneira o período de maturação do fruto.

PRALORAN (1970) compara certos fatores climáticos das regiões de origem dos abacateiros e diz da sua importância na adaptação dessas variedades em regiōes de condições climáticas semelhantes. Observa o autor que as condições climáticas afetam o teor de óleo dos frutos.

Em um estudo detalhado, MONTENEGRO (1956), dividiu o Estado de São Paulo em cinco regiões que influenciavam, através do clima, a época de amadurecimento do abacate (MAPA 1). Essas regiões, possuindo caracteristicas climáticas diferentes, forçavam a maturação de uma mesma cultivar em distintas épocas. Tomando como base a Região 2, denominada Limeira, esse estudo mostrou que na Região 1, denominada Ribeirão Preto, o abacate amadurece um mês antes, pois a referida região é mais quente, provocando uma maior precocidade. Já na Região 3, denominada Valinhos, sendo mais fria, o amadurecimento se dá um mês após da de Limeira; na Região 4, denominađa Buri, a maturação se dá um mês depois da Região 3 e dois meses depois da Região 2. Na Região 5, litoral, denominada São Sebastião, o período de amadurecimento é semelhante ao da Região 2, Limeira. 


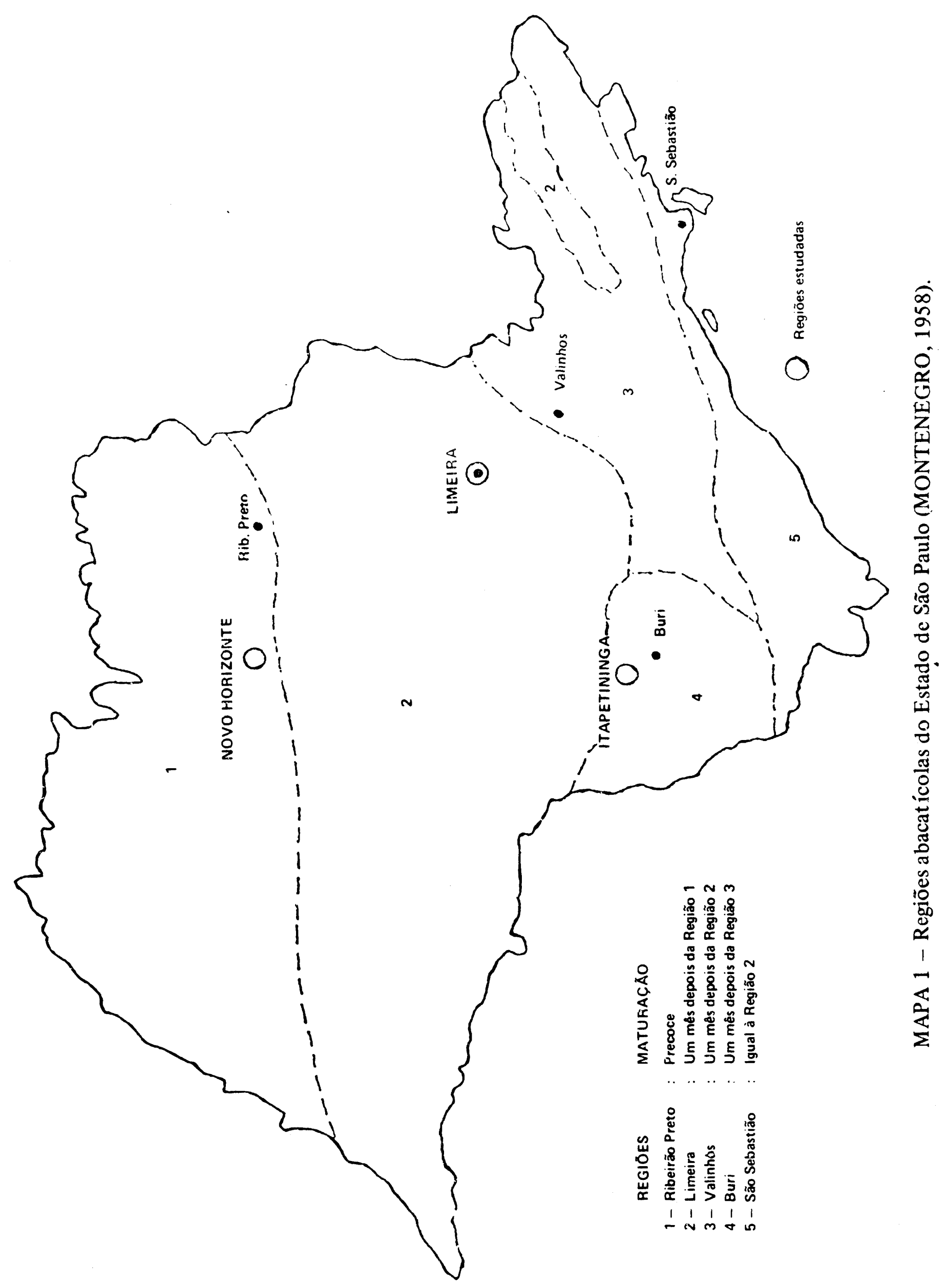


O abacateiro, Perséa americana Miller, é originário do continente americano, da região compreendida entre o centro do México e o Ístmo do Panamá (MONTENEGRO, 1960).

Segundo POPENOE (1924) todas as variedades cultivadas de abacateiros pertencem a mesma espécie botânica, e através de estudos botânicos, classificou-as, segundo os caracteres em comum, em três raças:

- Raça mexicana: plantas nativas de áreas elevadas do centro e do norte do México, com maturação do fruto no verão; sendo as mais resistentes ao frio;

- Raça guatemalense: plantas nativas de regiões elevadas da Guatemala e sul do México, cujo amadurecimento se dá no inverno e primavera; sendo menos resistentes ao frio;

- Raça antilhana: plantas nativas das regiões baixas dos trópicos, com maturação do fruto no verão e outono, sendo as mais suscetíveis ao frio. Essa influência climática também foi observada por MORIN (1965).

Além das variedades cultivadas, provenientes das três raças existem os híbridos, que se originaram por polinização cruzada entre cultivares de raças diferentes (STAHL, 1933).

POPENOE (1924) observa que a característica principal do abacate é o grande conteúdo em óleo que varia de 5 a $35 \%$ do peso da polpa fresca.

Segundo EIRIZ \& AZURMENDI (1958), o teor de óleo no abacate varia segundo as diferentes raças a que pertença a fruta; em geral, pode-se dizer que as da raça mexicana (provenientes de áreas elevadas do centro e norte do México) possuem teores mais elevados, podendo chegar até 26\% (na 'Puebla'); seguindo os frutos da raça guatemalense (das regiōes elevadas da Guatemala e sul do México), com 10 a $20 \%$ e finalmente os frutos da raça antilhana (das regiões baixas dos trópicos), com 4 a $14 \%$. Os híbridos, como o Fuerte (guatemalense x mexicana), na Califórnia, chegam a ter $30 \%$ de óleo na polpa.

CHANDLER (1962) cita que o teor de óleo na polpa do abacate, pode ser menor que $2 \%$ durante os dois primeiros meses de permanência do fruto na árvore, e depois aumenta lentamente, para na fase final, aumentar com muita rapidez. Na Flórida, a polpa dos frutos maduros das variedades cultivadas da raça das Indias Ocidentais (antilhana), tende a ter de 5 a $7 \%$ de óleo e as variedades da raça guatemalense e seus híbridos de 7,5 a $18 \%$. A cultivar 'Fuerte' (híbrido de guatemalense $\mathrm{x}$ mexicana) na Flórida contém de 13 a $17 \%$ de óleo, enquanto que na Califórnia, esse teor chega até a $25 \%$.

HAURY, GAILLARD \& PRALORAN (1970) estudando a influência do clima sobre o teor de óleo de diversas cultivares no Camerum, observaram que, a altitude, como um agente modificador do clima, é um fator imporiante na determinação da riqueza em óleo, em abacates. Assim, verificaram que havia uma tendência de aumento no teor de óleo nos frutos, com o aumento da altitude, nas regiões estudadas.

ST AHL (1933) analisando o teor de óleo de algumas cultivares em duas regiões da Flórida, com condições de umidade atmosférica diferentes, obteve o mesmo teor de oreo, para cada cultivar. 
CHURCH \& CHACE (1922) observaram que no abacate, as graxas se acumulam durante o desenvolvimento do fruto, enquanto que os glucídios diminuem.

MONCAYO (1968) trabalhando com cultivares no Equador, com fins de aprovei tamento alimentício e industrial, verificou que as variedades cultivadas em região de serra apresentaram maior quantidade de óleo que as cultivadas em região litorânea, sendo que a diferença no percentual de óleo, mostrou-se mais acentuada na cultivar 'Fuerte'.

Através do Quadro 1 pode-se avaliar os diferentes teores de óleo na polpa fresca do abacate, segundo alguns autores, em diferentes cultivares. Esses autores, em seus trabalhos, não mencionam a região de origem e em que condições ecológicas vegetavam as plantas que deram origem as amostras analisadas.

QUADRO 1 - Porcentagem de óleo na polpa fresca, segundo alguns autores, em diferentes cultivares de abacate.

\begin{tabular}{llccc}
\hline Cultivar & \multicolumn{1}{c}{ Raça } & $\begin{array}{c}\text { SCHWOB } \\
(1951)\end{array}$ & $\begin{array}{c}\text { MONTENEGRO } \\
(\mathbf{1 9 6 0 )}\end{array}$ & $\begin{array}{c}\text { TANGO et alii } \\
(1970)\end{array}$ \\
\hline 'Pollock' & Antilhana & 4,7 & 7,9 & 13,4 \\
'Simmonds' & Antilhana & 6,6 & - & 10,2 \\
'Waldin' & Antilhana & 6,3 & 10,0 & 6,9 \\
'Itzamna' & Guatemalense & - & 13,0 & 14,5 \\
'Linda' & Guatemalense & 12,3 & 17,3 & 15,2 \\
'Prince' & Guatemalense & - & - & 17,3 \\
'Wagner' & Guatemalense & 18,7 & 16,0 & 24,8 \\
'Taylor' & Guatemalense & 12,8 & 16,8 & - \\
'Collinson' & Híbrido & 11,5 & 13,0 & 11,5 \\
'Fuerte' & Híbrido & - & 35,0 & 25,5 \\
\hline
\end{tabular}

\section{MATERIAIS E MÉTODOS}

No período de dezembro de 1972 a novembro de 1973, colheu-se frutos de três cultivares de abacate: 'Wagner', 'Prince' e 'Collinson', em pomares de três regiões do Estado de São Paulo: Novo Horizonte, Limeira e Itapetininga, com o objetivo de determinar o estágio adequado de colheita, com vistas a um maior rendimento industrial.

Em cada região estudada foram selecionados três pomares que receberam as denominações de pomar A, B e C nos quais existem as cultivares estudadas: 'Wagner', 'Prince' e 'Collinson'.

Dentro de cada pomar foram selecionadas cinco árvores de cada cultivar com bom desenvolvimento vegetativo e em boas condições fitossanitárias. De cada árvore foram colhidos dois frutos dentre os mais desenvolvidos, que no conjunto (dez frutos) formaram a amostra a ser anaisada de cada cultivar.

A colheita dos frutos foi realizada nas datas constantes no Quadro 2, visando a análise do desenvolvimento do fruto, desde o início de sua formação até o estágio da maturą̧ão completa. 
QUADRO 2 - Datas de colheitas do fruto das cultivares estudadas.

\begin{tabular}{lccc}
\hline Regiōes & 'Wagner' & 'Prince' & 'Collinson' \\
\hline \hline \multirow{3}{*}{ Novo Horizonte } & $13 / 12 / 72$ & $13 / 12 / 72$ & $13 / 12 / 72$ \\
& $31 / 01 / 73$ & $31 / 01 / 73$ & $31 / 01 / 73$ \\
& $28 / 03 / 73$ & $28 / 03 / 73$ & $28 / 03 / 73$ \\
& $23 / 05 / 73$ & $23 / 05 / 73$ & $23 / 05 / 73$ \\
& $23 / 08 / 73$ & $23 / 08 / 73$ & - \\
Limeira & & $05 / 12 / 72$ & $05 / 12 / 72$ \\
& $05 / 12 / 72$ & $30 / 01 / 73$ & $30 / 01 / 73$ \\
& $30 / 01 / 73$ & $18 / 04 / 73$ & $18 / 04 / 73$ \\
& $18 / 04 / 73$ & $14 / 06 / 73$ & $14 / 06 / 73$ \\
& $14 / 06 / 73$ & $04 / 09 / 73$ & - \\
Itapetininga & $04 / 09 / 73$ & & $12 / 12 / 72$ \\
& & & $06 / 03 / 73$ \\
& $12 / 12 / 72$ & $12 / 12 / 72$ & $16 / 05 / 73$ \\
& $05 / 02 / 73$ & $06 / 02 / 73$ & $16 / 07 / 73$ \\
\hline
\end{tabular}

Após a colheita, os frutos etiquetados, e acondicionados cuidadosamente em sacos de polietileno, foram levados ao laboratório do Departamento de Tecnologia de Alimentos da Escola Superior de Agricultura "Luiz de Queiroz", em Piracicaba, SP, onde aferiu-se suas principais características físicas: peso do fruto inteiro; peso da casca (exocarpo); peso da polpa (mesocarpo) e peso da semente. Nas pesagens foi utilizada balança Triple Beam, com precisão de 0,1 grama. Em seguida, determinou-se a umidade natural da polpa, utilizando-se estufa Thelco, modelo 18, com circulação de ar quente, à temperatura de 105 a $110^{\circ} \mathrm{C}$, até peso constante; e balança Mettler $\mathrm{P} 1200 \mathrm{~N}$ com precisão de 0,01 grama.

A polpa, para posterior determinação do teor de óleo, foi seca parcialmente em estufa de circulação de ar quente à $65-70^{\circ} \mathrm{C}$ por 48 horas, acondicionada em vidros opa$\cos$, hermeticamente fechados e etiquetados.

Posteriormente, esse material foi levado ao Instituto de Tecnologia de Alimentos ITAL, Campinas, SP, onde efetuaram-se as análises do teor de óleo contido na polpa desidratada do abacate. Utilizou-se do método Ba 3-38 da American Oil Chemists' Society A.O.C.S. (MEHLENBACHER, HOPPER \& SALLEE, 1969), e como reagente o éter de petróleo (Baker Analyzed' Reagent, 30-600C, p.a.) e aparato Soxhlet.

$\mathrm{Na}$ última época de colheita, foi retirada também uma amostra extra de frutos das cultivares de cada pomar, que deixada amadurecer até o ponto de consumo, foi analisada. $O$ período de amadurecimento (entre colheita e amolecimento da polpa) foi de 4 a 8 dias.

O período de florescimento dos abacateiros foi de 20/08/72 a 20/09/72, na região de Novo Horizonte; de 01/09/72 a 30/09/72, na região de Limeira e de 15/09/72 a $10 / 11 / 72$, na região de Itapetininga. 
O período de florescimento do abacateiro não é muito preciso nas suas datas; há uma pequena porcentagem de florescimento antes e após essas datas, como mostra o trabalho de SAMPAIO (1974). As cultivares estudadas, 'Collinson', 'Prince' e 'Wagner', floresceram em maior proporção, no mesmo período, apesar da diferenca de maturação das mesmas.

Segundo FERREIRA et alii (1957), os parâmetros climáticos das regiões estudadas são os seguintes:

Novo Horizonte: altitude de $453 \mathrm{~m} ; 21028^{\prime} 02$ " de latitude sul e 49013'17" de longitude W.Gr.

Limeira: altitude de $542 \mathrm{~m}$; 22033'49" de latitude sul e 47024'15" de longitude W.Gr. Itapetininga: altitude de $670 \mathrm{~m}$; 23035'09" de latitude sul e 48002'51" de longitude W.Gr.

Do ponto de vista climático, segundo a Classificação do Clima, pelo Sistema Inter. nacional de Koeppen (SETZER, 1966), as regiões estudadas, possuem as seguintes caracteristicas:

Novo Horizonte: Aw - clima tropical com estiagem no inverno, com menos de $30 \mathrm{~mm}$ de chuva no mês mais seco, sendo a temperatura média do mês mais quente acima de $22^{\circ} \mathrm{C}$ e do mês mais frio acima de $180 \mathrm{C}$.

Limeira: $\mathrm{Cw}$ - clima temperado con estiagem no inverno, com menos de $30 \mathrm{~mm}$ de chuva no mês mais seco, sendo a temperatura média do mês mais quente acima de $220 \mathrm{C}$ e do mês mais frio abaixo de $180 \mathrm{C}$.

Itapetininga: $\mathrm{Cf}$ - clima temperado sem estação seca, com mais de $30 \mathrm{~mm}$ de chuva no mês mais seco, sendo a temperatura média do mês mais quente acima de $220 \mathrm{C}$ e do mês mais frio abaixo de $18{ }^{\circ} \mathrm{C}$.

Segundo a COMISSÃO DE SOLOS (1960), os solos das regiões estudadas são:

Novo Horizonte: Podzólico Vermelho-Amarelo "Intergrade" para Latossol VermelhoAmarelo.

Limeira: Solios Podzolizados de Lins e Marília, variação Lins.

Itapetininga: Latossol Vermelho-Escuro Orto.

Os Quadros 3 e 4 mostram as características físicas e químicas dos solos, através de amostras de terra retiradas dos pomares estudados, e arıalisadas pelas Seções de Fertilidade do Solo e Pedologia, do Instituto Agronômico do Estado de São Paulo, Campinas, SP. 
QUADRO 3 - Análise química dos solos dos pomares estudados.

\begin{tabular}{|c|c|c|c|c|c|c|c|}
\hline \multirow{2}{*}{ Regiões } & \multirow{2}{*}{ Pomar } & \multirow{2}{*}{$\mathrm{pH}$} & \multirow{2}{*}{$\mathrm{C} \%$} & \multicolumn{4}{|c|}{ e.mg por $100 \mathrm{ml}$ de T.F.S.A.(1) } \\
\hline & & & & $\mathrm{PO}_{4}^{---}$ & $\mathrm{K}^{+}$ & $\mathrm{Ca}^{+++} \mathrm{Mg}^{++}$ & $\mathrm{Al}^{+++}$ \\
\hline \multirow{3}{*}{$\begin{array}{l}\text { Novo } \\
\text { Honzonte }\end{array}$} & A & $5,4 i$ & 0,70 & 0,020 & 0,13 & 1,91 & - \\
\hline & B & 5,26 & 0,80 & 0,010 & 0,27 & 1,42 & - \\
\hline & C & 5,51 & 0,80 & 0,005 & 0,29 & 1,26 & - \\
\hline \multirow{3}{*}{ Limeira } & A & 5,47 & 1,90 & 0,080 & 0,60 & 4,96 & - \\
\hline & B & 5,12 & 1,80 & 0,040 & 0,25 & 3,17 & 0,86 \\
\hline & C & 5,30 & 2,70 & 0,005 & 0,06 & 2,09 & 0,39 \\
\hline \multirow{3}{*}{ Itapetininga } & A & 4,86 & 2,70 & 0,050 & 0,33 & 2,30 & 0,65 \\
\hline & B & 5,23 & 1,80 & 0,040 & 0,16 & 1,90 & 0,43 \\
\hline & C & 4,74 & 1,30 & 0,020 & 0,07 & 1,42 & 0,76 \\
\hline
\end{tabular}

(1) e.mg = equivalente-miligrama

T.F.S.A. = terra fina seca ao ar (partículas menores que $2 \mathrm{~mm}$ ).

QUADRO 4 - Análise física (granulométrica) dos solos dos pomares estudados.

\begin{tabular}{lcccccl}
\hline Regiões & Pomar & $\begin{array}{c}\text { Argila } \\
(\%)\end{array}$ & $\begin{array}{c}\text { Limo } \\
(\%)\end{array}$ & $\begin{array}{c}\text { Areia } \\
\text { fina }(\%)\end{array}$ & $\begin{array}{c}\text { Areia } \\
\text { grossa }(\%)\end{array}$ & Classificação \\
\hline \multirow{3}{*}{ Novo Horizonte } & $\mathrm{A}$ & 8,7 & 0,0 & 72,8 & 18,5 & Fino arenoso \\
& $\mathrm{B}$ & 11,2 & 0,0 & 77,9 & 10,9 & Fino arenoso \\
& $\mathrm{C}$ & 10,0 & 1,2 & 74,4 & 14,4 & Fino arenoso \\
\multirow{4}{*}{ Limeira } & $\mathrm{A}$ & 26,2 & 5,0 & 38,6 & 30,2 & Barrento \\
& $\mathrm{B}$ & 56,2 & 5,0 & 30,7 & 8,1 & Argiloso \\
& $\mathrm{C}$ & 50,0 & 11,2 & 25,9 & 12,9 & Argiloso \\
& & & & & & \\
Itapetininga & $\mathrm{A}$ & 45,0 & 6,2 & 36,0 & 12,8 & Argiloso \\
& $\mathrm{B}$ & 42,3 & 5,8 & 39,4 & 12,5 & Argiloso \\
& $\mathrm{C}$ & 42,5 & 6,2 & 35,7 & 15,6 & Argiloso \\
\hline
\end{tabular}

Os dados de precipitaçâo pluviométrica no transcorrer do experimento, foram obtidos na Seção de Climatologia Agrícola do Instituto Agronômico do Estado de São. Paulo, Campinas, SP (Quadro 5). 
QUADRO 5 - Dados de precipitaçäo pluviométrica em $\mathrm{mm}$ de chuva por mês (Fonte: I.A.C.)

\begin{tabular}{|c|c|c|c|c|c|c|c|c|c|}
\hline \multirow{2}{*}{ Meses } & \multicolumn{3}{|c|}{ Pindorama (*) } & \multicolumn{3}{|c|}{ Limeira } & \multicolumn{3}{|c|}{ Itapetininga } \\
\hline & 1972 & 1973 & $\begin{array}{c}\text { Média de } \\
51 \text { a } 72\end{array}$ & 1972 & 1973 & $\begin{array}{c}\text { Média de } \\
40 \text { a } 72\end{array}$ & 1972 & 1973 & $\begin{array}{l}\text { Média de } \\
38 \text { a } 72\end{array}$ \\
\hline Jan. & 282 & 140 & 233 & 272 & 95 & 240 & 307 & 183 & 212 \\
\hline Fev. & 286 & 49 & 222 & 245 & 143 & 210 & 346 & 350 & 177 \\
\hline Mar. & 171 & 178 & 141 & 54 & 171 & 165 & 86 & 63 & 139 \\
\hline Abr. & 73 & 135 & 53 & 75 & 72 & 62 & 45 & 57 & 57 \\
\hline Mai. & 55 & 52 & 52 & 37 & 43 & 47 & 35 & 70 & 53 \\
\hline Jun. & 0 & 26 & 37 & 2 & 32 & 34 & 6 & 52 & 47 \\
\hline Jul. & 109 & 27 & 24 & 129 & 64 & 24 & 144 & 53 & 44 \\
\hline Ago. & 58 & 4 & 24 & 74 & .18 & 29 & 81 & 50 & 38 \\
\hline Set. & 61 & 27 & 44 & 91 & 51 & 60 & 185 & 76 & 68 \\
\hline Out. & 204 & 130 & 123 & 180 & 103 & 134 & 244 & 148 & 127 \\
\hline Nov. & 102 & 86 & 116 & 129 & 154 & 148 & 96 & 103 & 111 \\
\hline Dez. & 127 & 187 & 188 & 202 & 157 & 223 & 140 & 285 & 170 \\
\hline Ano & 1528 & 1041 & 1257 & 1490 & 1103 & 1376 & 1715 & 1500 & 1243 \\
\hline
\end{tabular}

(*) Por falta de dados de chuva em Novo Horizonte, foram tomados os de Pindorama, onde existe uma estação meteorológica oficial, distando $50 \mathrm{~km}$ de Novo Horizonte. Os parâmetros climáticos de Pindorama são: 562 m de altitude, 21010' de latitude e 48054' de longitude.

Com o objetivo de uma melhor caracterização das temperaturas mensais das regiões estudadas, dá-se no Quadro 6 uma estimativa das temperaturas mensais de acordo com a metodologia utilizada por PINTO, ORTOLANI \& ALFONSI (1972), baseada na altitude e latitude da região.

QUADRO 6 - Dados de temperatura média mensal estimada, em função da altitude e da latitude da localidade estudada (PINTO, ORTOLANI \& ALFONSI, 1972)

\begin{tabular}{lccc}
\hline Meses & Novo Horizonte & Limeira & Itapetininga \\
\hline \hline Janeiro & 24,3 & 23,4 & 22,3 \\
Fevereiro & 24,2 & 23,3 & 22,4 \\
Março & 23,8 & 22,8 & 21,7 \\
Abril & 22,1 & 21,0 & 19,8 \\
Maio & 19,7 & 18,5 & 17,2 \\
Junho & 18,3 & 17,0 & 15,7 \\
Julho & 18,2 & 16,8 & 15,3 \\
Agosto & 19,6 & 18,2 & 16,6 \\
Setembro & 21,7 & 20,0 & 18,1 \\
Outubro & 22,8 & 21,2 & 19,5 \\
Novembro & 23,6 & 22,3 & 20,8 \\
Dezembro & 23,9 & 22,9 & 21,7 \\
\hline Ano & 21,8 & 20,6 & 19,2 \\
\hline
\end{tabular}




\section{RESULTADOS E DISCUSSÃO}

A análise estatística dos dados obtidos (média de 10 frutos), foi efetuada através de análise de variânciạ, em blocos casualizados dentro das regiőes, e inteiramente casualizado entre as regiões. Procedeu-se à comparação das médias pelo teste de Tukey. Para a comparação dos efeitos de variação - cultivares, regiōes e estágios de maturação, utilizou-se de esquema fatorial $3 \times 3 \times 2$.

Os dados das características físicas đo fruto, no estágio final de maturação são os seguintes: 

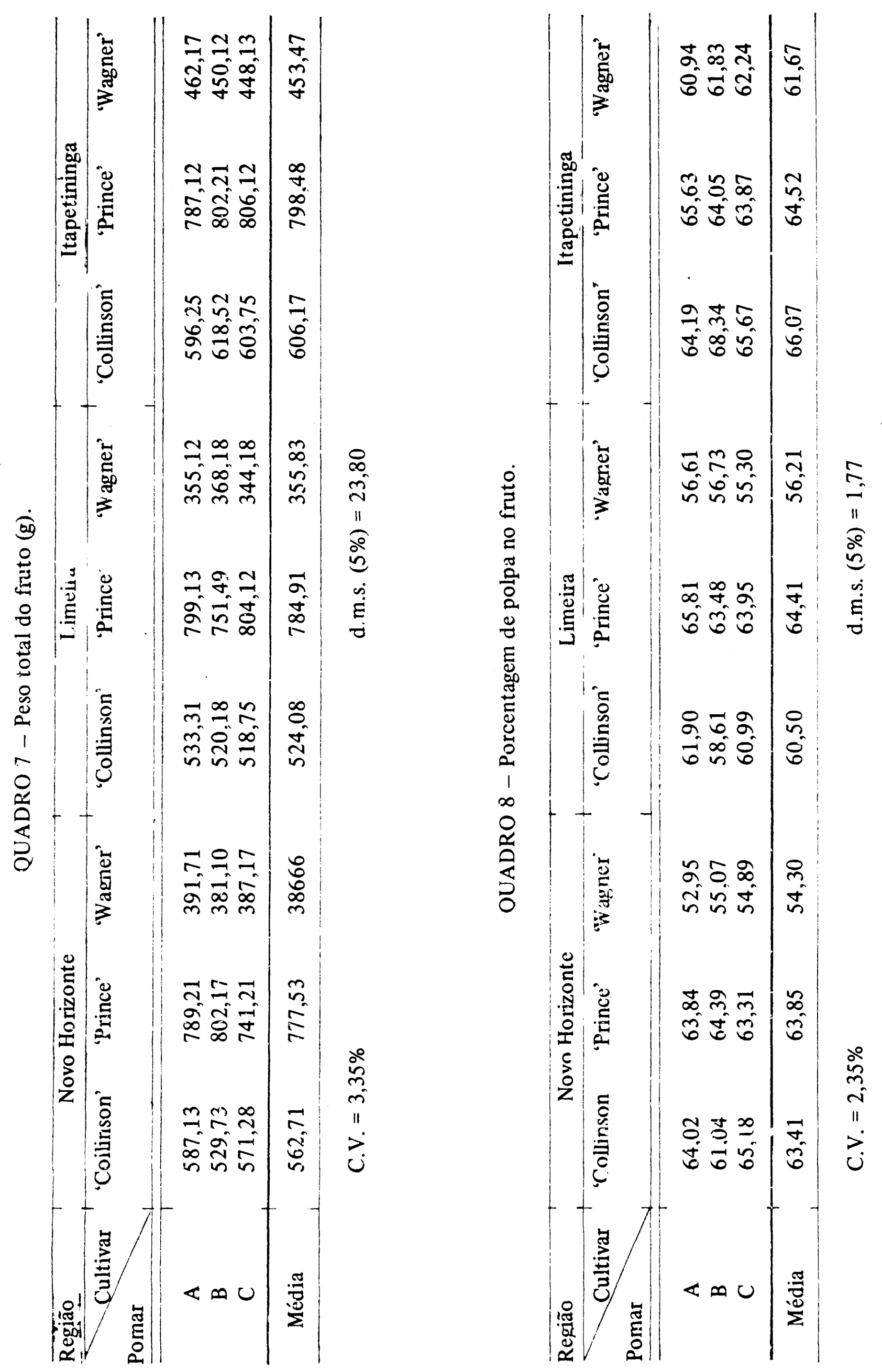


Os dados obtidos de peso total do fruto; porcentagem de polpa, de casca e de semente no fruto, apresentaram valores de $\mathrm{F}$ para Regiōes e Cultivares, significativos ạo nivel de $1 \%$.

Os dados obtidos dos teores de óleo na polpa, durante o desenvolvimento do fruto. dentro de cada região, são:

QUADRO 11 - Porcentagem de óleo na polpa, na região de Novo Horizonte.

\begin{tabular}{|c|c|c|c|c|c|c|c|c|c|c|}
\hline \multicolumn{2}{|c|}{ Cultivar } & \multicolumn{2}{|c|}{ 'Collinson' } & \multirow[b]{2}{*}{ C } & \multicolumn{2}{|r|}{ Prince } & \multicolumn{3}{|r|}{ 'Wagner' } & \multirow{2}{*}{$\mathrm{C}$} \\
\hline & $\begin{array}{l}\text { Pomar } \\
\text { a }\end{array}$ & A & B & & A & B & $\mathrm{C}$ & A & B & \\
\hline $1 a$ & $13 / 12 / 72$ & 2,23 & 2,28 & 2,22 & 1,28 & 1,42 & 1,29 & 1,97 & 1,93 & 1,82 \\
\hline $2 a$ & & 3 & & 3,73 & & & 1 , & 4 & & 2,97 \\
\hline $3 a$ & $2 \varepsilon$ & 6 , & 7 , & 6,36 & 3 , & 4 & 4,08 & 6,97 & 4 & 7,62 \\
\hline $4 \mathrm{a}$ & $23 / 05 / 73$ & 10,50 & 12,80 & 11,46 & 9,00 & 9,29 & 10,30 & 12,73 & 12,08 & 11,75 \\
\hline 0 & $23 / 08 / 73$ & - & - & - & 15,83 & 16,13 & 16,53 & 19,37 & 20,08 & 19,88 \\
\hline
\end{tabular}

C.V. $=8,61 \%$

QUADRO 12 - Porcentagem de óleo na polpa, na região de Limeira.

\begin{tabular}{|c|c|c|c|c|c|c|c|c|c|c|}
\hline \multirow{2}{*}{\multicolumn{2}{|c|}{$\underbrace{\text { Cultivar }}_{\text {Data }}$}} & \multirow{2}{*}{\multicolumn{2}{|c|}{$\frac{-}{-} \frac{\text { Collinson }}{\mathrm{A}} \quad \frac{\mathrm{B}}{}$}} & \multirow{2}{*}{$\bar{C}$} & \multirow[b]{2}{*}{ A } & \multicolumn{2}{|c|}{ 'Prince' } & \multicolumn{3}{|c|}{ 'Wagner' } \\
\hline & & & & & & B & $\mathrm{C}$ & A & $\mathrm{B}$ & $\mathrm{C}$ \\
\hline $1 \mathrm{a}$ & $05 / 12 / 72$ & 1,79 & 2,07 & 1,85 & 0,94 & 0,89 & 1,06 & 1,43 & 1,69 & 1,40 \\
\hline $2 \mathrm{a}$ & $30 / 01 / 73$ & 2,54 & 2,32 & 2,43 & 1,44 & 1,31 & 1,62 & 1,92 & 2,26 & 2,67 \\
\hline $3 a$ & $18 / 04 / 73$ & 6,58 & 6,99 & 6,26 & 4,46 & 5,08 & 4,50 & 6,95 & 7.80 & 7,87 \\
\hline $4 !$ & $14 / 06 / 73$ & 12,64 & 14,03 & 12,78 & 7,59 & 8,52 & 9,27 & 12,05 & 10,64 & 12,13 \\
\hline $5 \mathrm{a}$ & $04 / 09 / 73$ & - & - & - & 17,05 & 16,42 & 16,36 & 19,85 & 20,74 & 21,21 \\
\hline
\end{tabular}

OUADRO 13 - Porcentagem de óleo na polpa, na região de Itapetininga.

\begin{tabular}{|c|c|c|c|c|c|c|c|c|c|c|}
\hline \multicolumn{3}{|c|}{ Cuitivar } & \multicolumn{2}{|c|}{ 'Tullinson' } & \multicolumn{3}{|c|}{ 'Prince' } & \multicolumn{3}{|c|}{ 'Wagner' } \\
\hline & Lente & A & B & $\mathrm{C}$ & A & E & $\mathrm{C}$ & A & B & C \\
\hline $1 \stackrel{a}{a}$ & $12 / 12 / 72$ & 1,47 & 1,56 & 1,60 & 0,90 & 0,82 & 0,92 & 1,35 & 1,49 & 1,41 \\
\hline $2 ?$ & $06 / 02 / 73$ & 2,51 & 2,17 & 2,55 & 1,29 & 1,30 & 1,22 & 1,72 & 2,06 & 2,03 \\
\hline $3 \mathfrak{a}$ & $16 / 05 / 73$ & 6,78 & 7,46 & 7,71 & 5,86 & 6,24 & 5,70 & 7,39 & 9,44 & 7,75 \\
\hline $4 a$ & $16 / 07 / 73$ & 12,69 & 14,16 & 14,11 & 9,83 & 8,61 & 9,22 & 12,22 & 13,99 & 11,98 \\
\hline 5 a & $07 / 11 / 73$ & - & - & - & 17,78 & $1 \% .56$ & 16,93 & 20,12 & 21,75 & 22,01 \\
\hline
\end{tabular}

C.V. $=9,87 \%$ 
As análises estatísticas da porcentagem de óleo na polpa do abacate, dentro da região, mostraram o valor de $\mathrm{F}$ para Blocos (Pomares) não significativo e para as Cultivares foi significativo ao nível de $1 \%$ nas três regiões.

Os dados obtidos da porcentagem de óleo na polpa, entre regiões, no estágio final de maturação, com frutos verdes e deixados amadurecer, são os seguintes: QUADRO 14

$\mathrm{O}$ valor de $\mathrm{F}$ para as Cultivares, para as Regiões e para os Estágios foi significativo ao nível de $1 \%$.

Os dacios obtidos na porcentagem de óleo no fruto (da polpa em relação ao fruto inteiro), entre regiões, no estágio final de maturação, săo:

$\mathrm{O}$ valor de $\mathrm{F}$ para as Cultivares dentro das regiões, e entre regioes, foi signticativo aO nivel de $1 \%$.

Os dados obtidos da porcentagem de água na polpa, entre regiões, no estágio final de maturação, com frutos verdes e deixados amadurecer, são os seguintes conforme a demonstração do Quadro 16.

QUADRO 16

O valor de $F$ para Cultivares, Regiões e Estágios foi significativo ao nivel de $1 \%$.

Os Gráficos 1 a 6 apresentam a evolução verificada, durante o desenvolvimento do abacate, desde a sua formação até a maturação final. Os valores utilizados nos gráficos são média dos três pomares estudados em cada região.

GRÁFICOS 1 a 6 




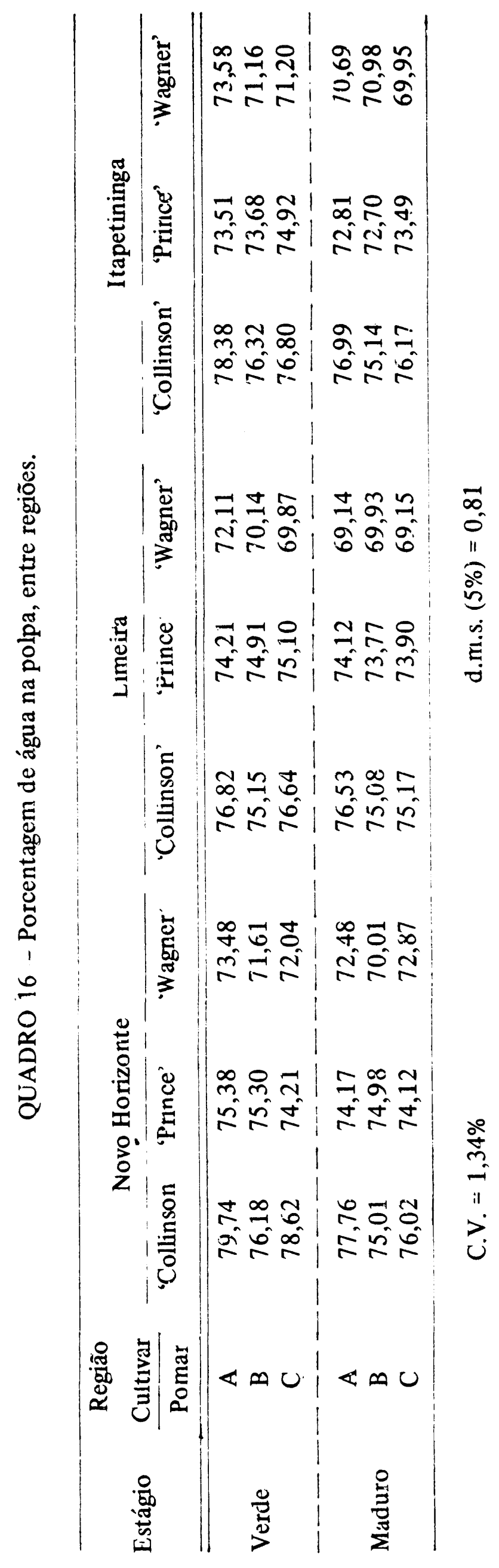



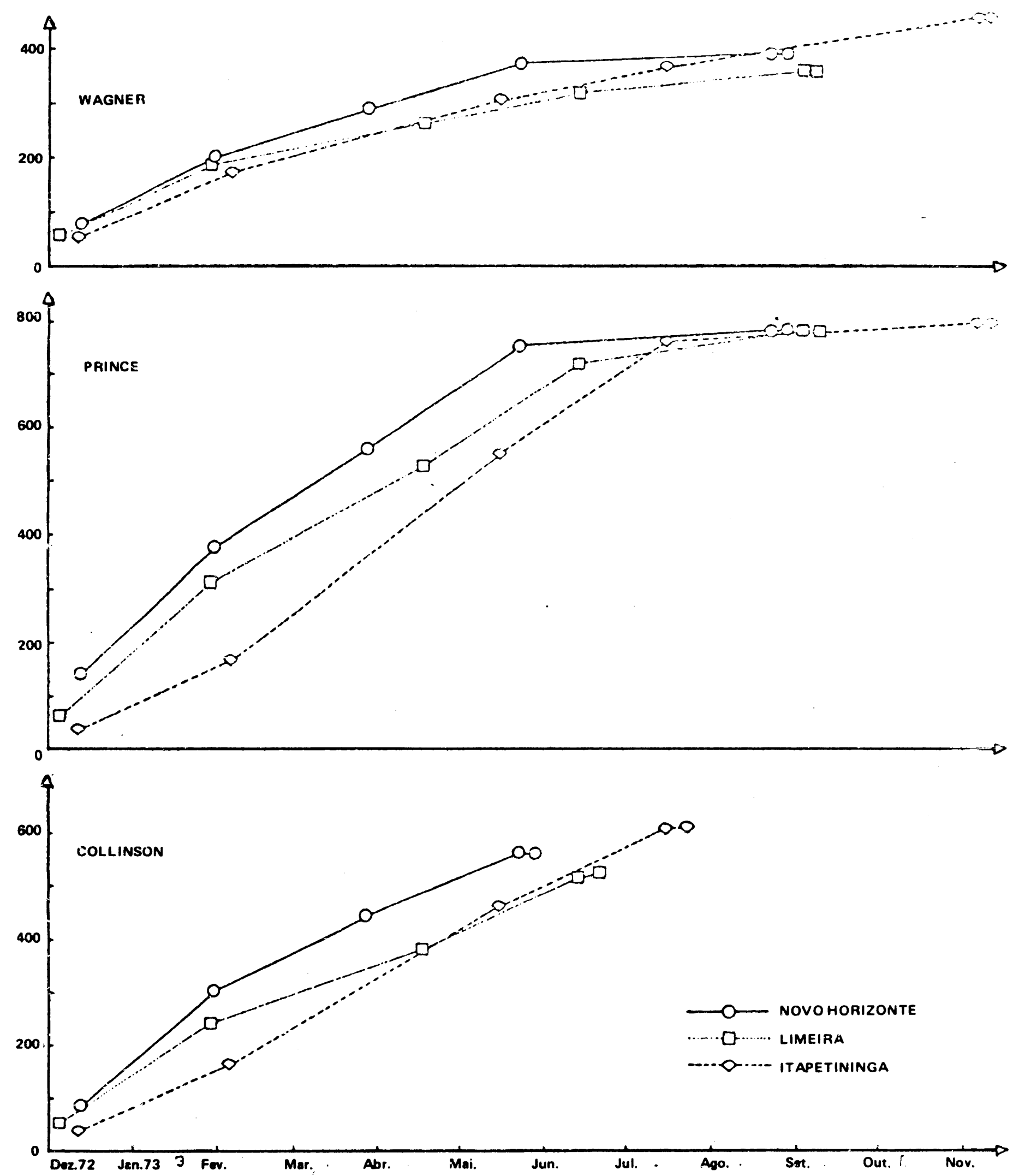

GRÁFICO 1 - Peso total do fruto (gramas). 




GRÁFICO 2 - Peso da semente (gramas). 




GRÁFICO 3 - Peso da cascà (gramas) 




GRÁFICO 4 - Peso da polpa (gramas) 



GRĀFICO 5 - Porcentagem de água na polpa. 



GRÁFICO 6 - Porcentageni de óleo na polpa. 
A discussão dos resultados foi subdividida em:

a) Características físicas do fruto - É bastante conhecido na literatura frutícola que regiões quentes produzem normalmente frutos de maior tamanho que regióes mais frias (ULRICH, 1952; MONTENEGRO, 1958).

No presente trabalho, constatou-se, no estágio final de maturação, difereriças significativas entre o peso dos frutos das regiões. Analisando-se este fato, em relação a temperatura mencionada por aqueles autores, como causadora deste efeito, não se observou tal ação. Pode-se notar, através do Quadro 7, que os frutos da região mais fria (Itapetininga) apresentaram maior peso; os da região de temperatura intermediária (Limeira) os de menor peso; e na região mais quente (Novo Horizonte) os frutos apresentaram peso intermediário.

É provável que as diferenças constatadas entre os pesos dos frutos das diferentes regiões tenham sido motivados pelas diferentes idades dos pomares. Nesse aspecto, se constata uma relação entre idade do pomar e peso do fruto. Assim, os pomares de Itapetininga, os mais novos (8 a 10 anos) produziram frutos de maior peso; os de Novo Horizonte, intermediário na idade (10 a 15 anos) produziram frutos de peso intermediário; os de Limeira, os mais velhos (15 a 40 anos) produziram frutos de menor peso, no estágio final de maturação.

A produção de frutos pequenos em pomares velhos e de frutos grandes em pomares novos é fato conhecido e mencionado por vários autores (ULRICH, 1952; MONTENEGRO, 1956; GONZALEZ-CICILIA, 1960;CAMERON \& FROST, 1968).

Os Gráficos 1 a 4, apresentam o aumento em peso progressivo do fruto e de suas partes constituintes, polpa, semente e casca. Observa-se nesses gráficos que as retas de desenvolvimento desses componentes, são bem concordantes entre si. Outro fato bem evidenciado, é a influência das regiões no desenvolvimento do fruto e de suas partes, mostrando a precocidade de desenvolvimento nas regiões mais quentes.

A significação constatada entre as médias de porcentagem de polpa, semente e casca, em relação ao peso total do fruto (Quadros 7 a 10) entre a região de Itapetininga e as outras duas regiões, se justifica, pelo aumento do peso do fruto observado nas regiões, motivado, provavelmente, pela idade dos pomares. É normal que as diferentes proporções das partes constituintes do fruto (polpa, semente e casca), com o aumento do peso total do fruto, corresponda a variações profundas nessas proporções. Assim, para a polpa, que de maneira geral corresponde a $80 \%$ do peso total do fruto, um aumento de peso deste, corresponderá a um aumento proporcional bem maior, daí a razão da diferença significativa entre as regiões (Quadro 8). No caso da semente e da casca, que representam apenas cerca de $10 \%$ cada um, do peso total do fruto, o aumento deste, corresponderá a um aumento, em números absolutos, tão pequeno, que porcentualmente pode ser bem maior do que para frutos pequenos. Isto justifica a diferença significativa da porcentagem de casca e semente entre as regiões (Quadros 9 e 10).

b) Influência do clima na maturação - É conhecido através da literatura hortícola que a planta necessita determinadas "unidades térmicas", para completar o seu ciclo de frutificação (do florescimento à maturação) do fruto, calculando-se esse período através 
da soma dos excedentes de graus de temperatura acima de um mínimo, durante todo o ciclo de frutificação. Esse fato foi observado por Barnard, citado por MONTENEGRO (1958) que mostrou quais as necessidades totais da temperatura para as diferentes espécies cítricas, assim, o Pomelo requeria de 6.000 a $6.7000^{\circ}$; o Limão $2.0000 \mathrm{C}$; a Laranja Baianinha de 3.000 a $3.400{ }^{\circ} \mathrm{C}$ e a Valência de $2.600{ }^{\circ} \mathrm{C}$.

O total de "unidades térmicas" que cada planta necessita, pode, conforme o clima da região, provocar uma precocidade ou retardamento na época de maturação. Segundo REUTHER \& RIOS-CASTAÑO (1969), plantas cítricas na Califórnia, em clima subtropical apresentaram um ciclo de desenvolvimento mais longo que as mesmas plantas na Colômbia, ern um clima tropical.

No presente trabalho, de maneira muito marcante, foi constatado a influência do clima sobre o ciclo de frutificação no abacateiro. Ficaram assim comprovados as observações de MONTENEGRO (1956) relativas a influência de diferentes regiões do Estado de São Paulo, no período de amadurecimento dos abacates (Mapa 1). No Gráfico 1, observa-se que para cada época houve uma relação entre o clima da região e o peso do fruto. Em todas as cultivares estudadas, os frutos tiveram uma tendência de apresentarem durante o desenvolvimento, maior peso na região mais quente; valores médios na região intermediária e baixos na região mais fria; mostrando dessa maneira, que em uma determinada data os frutos se apresentavam em diferentes graus de desenvolvimento fisiológico; mais adiantados na região mais quente, médios na região intermediária e mais atrasados na região fria.

A influência da temperatura sobre o processo de maturação do abacate é conhecida, principalmente através de estudos feitos por BIALE (1941); PRATT \& BIALE (1944), e BIALE \& YOUNG (1962), em abacateiros da cultivar 'Fuerte', na Califórnia, mostrando que o abaixamento da temperatura diminui o processo respiratório, aumentando dessa maneira o período de maturação.

Tal fato se reveste de grande importância sócio-econômica, pois não somente vai possibilitar uma melhor distribuição desta fruta nos mercados como também proporcionar às indústrias, a matéria-prima por mais amplo período. Assim, exemplificando, o 'Wagner', foi colhido em agosto, em Novo Horizonte; em setembro, em Limeira; e em novembro, em Itapetininga, o que vem possibilitaĩ a sua exploração nos mercados e com fins industriais por um periodo mais amplo, apenas relacionando-se as épocas de maturação nas regiões quentes até as regiões frias.

c) Óleo: evolução, teor e influência ecológica - Os resultados obtidos (Gráfico 6, e Quadros 11 a 13) mostram que o teor de óleo na polpa evolui no início lentamente para no final crescer em maior proporção, alcançando o ápice no final da maturação. Tal fato também foi verificado por CHURCH \& CHACE (1922); ULRICH (1952); CHANDLER (1962); TIJERO (1964) e MONTENEGRO (1960).

Observou-se que à medida que o fruto se desenvolve, acentuam-se as diferenças no teor de óleo entre as cultivares estudadas, o qual concorda com MONTENEGRO (1956); EIRIZ \& AZURMENDI (1958) e PRALORAN (1970), os quais citam que o teor de óleo no abacate varia segundo as diferentes raças a que pertença 0 abacate e que isso é uma característica de cada cultivar. Na região mais fria, as diferenças acentuaram-se mais lentamente. 
Dentro de cada região, observou-se que apesar dos diferentes fatores ambientais, tais como as características físico-químicas do solo e tratos culturais dos pomares, estatisticamente, estas características não foram suficientes para determinar variações significativas no teor de óleo entre os pomares. Mesmo com relação a idade, verificou-se que na região de Limeira, os pomares com idades diferentes (pomar A - Fazenda Citra, plantas com 30 a 40 anos de idade; B - Chácara Paineira, com 15 a 20 anos, e C - Chácara Repouso, com 15 a 20 anos), as cultivares não apresentaram diferença significativa no teor de óleo.

Entre os frutos das diferentes regiōes, constatou-se diferenças significativas com relação ao teor de óleo, no estágio final de maturação. Observou-se que a mesma cultivar, na região de Itapetininga apresentou maior teor de óleo que na de Limeira, e esta por sua vez mais que na de Novo Horizonte (Quadro 15).

Essas observações mostram a influência do clima, provavelmente através do seu fator temperatura, sobre o teor de óleo na polpa do abacate. Assim, entre as regiões estudadas, quanto mais fria a região, maior foi o teor de óleo encontrado. Tal fato concorda com CHANDLER (1962); MONCAYO (1968); e HAURY, GAILLARD \& PRALORAN (1970).

Em média, nos três pomares de cada região, no estágio final de maturação, a poịpa apresentou: para a cultivar 'Wagner', em Novo Horizonte, 19,78\% de óleo; em Limeira, $20,60 \%$; e em Itapetininga, $21,29 \%$. Já na cultivar 'Prince', havià $16,17 \%$ em Novo Horizonte; $16,61 \%$ em Limeira; e 17,42\% em Itapetininga. Na cultivar 'Collinson', havia $11,58 \%$ em Novo Horizonte; $13,15 \%$ em Limeira; e 13,65\% em Itapetininga (Quadro 14).

Observou-se que houve um aumento no teor de óleo na polpa, na fase final de maturação entre o estágio de fruto recém-colhido (polpa dura) e o maduro para consumo (polpa mole), conforme Quadro 14. O mesmo fato foi observado por BIALE \& YOUNG (1962). Isto provavelmente não se deve a um aumento real de óleo na polpa, mas sim a um aumento na porcentagem de óleo devido a uma perda mais acentuada de água que ocorre nesse curto período (4 a 8 dias), conforme Quadro 16.

\section{CONCLUSO̊ES}

Dos estudos realizados chegou-se às seguintes conclusões:

1 - Constatou-se uma dilatação no ciclo de frutificação (do florescimento à maturação) do abacate, à medida que o clima dà região torna-se mais frio. Relacionando-se as regiões estudadas, em uma determinada data, os frutos apresentavam diferentes graus de desenvolvimento fisiológico; mais adiantados na região mais quente e mais atrasados na região mais fria.

2 - Constatou-se a influência do clima sobre o teor de óleo no estágio final de maturação. Considera-se que o fator climático a influenciar o teor de óleo foi provavelmente a temperatura, determinando teores mais elevados nas regiões mais frias. 
3 - Constatou-se aumento no teor de óleo na polpa, enquanto o abacate permaneceu na árvore. A evolução do teor de óleo na polpa do abacate se processa lentamente no início, acentuando-se no final do desenvolvimento do fruto.

7 - Não se constatou influência do solo, dos tratos culturais e da idade dos pomares sobre o teor de óleo na polpa do abacate.

\section{SUMMARY}

\section{ECOLOGICAL INFLUENCE ON FRUIT DEVELOPMENT AND ON OIL CONTENT OF AVOCADO PULP (Persea americana MILLER)}

It was conducted an experiment to verify the evolution of oil in avocado pulp in three ecologically different regions of São Paulo State (Novo Horizonte, Limeira and Itapetininga). The purpose was to determine the suitable stage fruit crop for a higher industrial yield in oil production.

In each region it was utilized three orchards and in each orchard it was selected five trees of 'Wagner', 'Prince' and 'Collinson' cultivars, picking up two fruits per tree and the set (ten fruits) was the sample per cultivar to be analysed.

Harvestings were done in pre-determined time, aiming at the analysis of fruit development, from it setting to maturation time. It was also accomplished analysis of samples kept to ripe till consumption point (soft pulp).

From the studies it was verified that the regional climate influences fruiting cycle (from flowering to ripening) of avocado. Relating the regions studied at a given date, fruits presented different degree of physiological development hastening in hotter region and delaying in colder region.

In the final stage of avocado maturation, it was verified an influence of climate upon pulp oil content. It is considered that the climate factor that influences oil content was probably temperature, determining higher contents in colder region.

It was observed that the evolution of pulp oil content of avocado processes slowly at begining, accentuating in the final of fruit development. It was verified increase in pulp oil while the fruit was kept in the tree.

It was not verified influence of soil characteristics, cultural practices and age of ochard upon pulp oil content of avocado. 


\section{LITERATURA CITADA}

BIALE, J.B., 1941. The climateric rise in respiration rate of the Furete avocado fruit. Proc. Amer. Soc. Hort. Sc., $39: 137-142$.

\& YOUNG, R.E., 1962. Bioquímica de la maturación de los frutos. Endeavour. Londres, 21(83/84):164-174.

CAMERON, J.W. \& FROST, H.B., 1968. Genetics, Breeding and Nuclear Embryony. IN: The Citrus Industry. University of California, Division of Agricultural Sciences, 2:325-370.

CHANDLER, W.H., 1962. Aguacate. IN : Frutales de hoja perenne. Traduzido por José Luiz de la Roma. Ed. Hispano-Americana, México. p. 254-275.

CHURCH, C.G. \& CHACE, E.M., 1922. Some changes in the composition of California Avocados during growth. United States Department of Agriculture. Bull. n. 1073, Washington, 1-22.

COMISSÃO DE SOLOS, 1960. Levantamento de reconhecimento dos solos do Estado de São Paulo. Serv. Nac. Pesq. Agron., Bol. no 12, Min. Agric. CNEPA, Rio de Janeiro, 1.634.

CORTÉS, A.R. et alii, 1971. Estudio de las condiciones químicas y tecnológicas para una posible industrialización de la palta (aguacate). Revista de Agroquímica y Tecnologia de Alimentos. Inst. Agroquim. y Tec. de Alim., Valência, Espanha, 11(2):295-300.

DUPAIGNE, P., 1970. Une nouvelle specialite pharmaceutique: l'insaponifiable de l'huile d'avocat. Fruits, I.F.A.C., France, 25(12) 915-916.

EIRIZ, F.A. \& AZURMENDI, J.M.O., 1958. Variedades comerciales de aguacates. Hojas divulgadoras no 2-69-H. Ministério de Agricultura de Madrid, 1-23.

FERREIRA, J.P. et alii, 1957. Enciclopédia dos Municípios Brasileiros. I.B.G.E. Rio de Janeiro, $28: 71-77 ; 193-195 ; 29: 446-450$.

GONZALEZ-SICILİA, E., 1960. Genética - Mejora de variedades. IN : El Cultivo de los Agrios. Instituto Nacional de Investigaciones Agronomicas. Ministério de Agricultura, Madrid, 357-389.

HAENDLER, L., 1965. L'huile d'avocat et les produits dérivés du fruit. Fruits. I.F.A.C., France, 20(11):625-633. $911-914$

HAURY, A.; GAILlARD, J.P. \& PRALORAN, J.C., 1970. Contribution à l'etude de l'influence du climat sur la teneur en huile des avocates. Fruits, I.F.A.C., France, 25(9):613-619.

IZURIETA, O.B., 1970. Obtenção de óleo de abacate. Tese apresentada para obtenção do títuío de Mestre em Engenharia de Alimentos. Faculdade de Tecnologia de Alimentos. Univ. Est. de Campinas, SP, 1-39.

LOVE, H.T., 1944. Avocado Oil Studies. California Avocado Society. Yearbook, California, 35-36.

MEHLENBACKER, V.C.;HOPPER, T.H. \& SALLEE, E.M., 1969. Official and tentative methods of the American Oil Chemists' Society. Chicago, Illinois, U.S.A., 2a ed. A.D.C.S., Official Method Ba 3-38, 1-3.

MONCAYO, P.Z., 1968. El contenido de aceite en variedades de aguacate cultivadas en el Ecuador. Tesis de grado. Fac. Ing. Agr. Med. Vet., Universidad Central Quito, Equador, 1-42.

MONTENEGRO, H.W.S., 1956. Contribuiçăo para o estudo pomológico do abacateiro. Tese de Livre-Docente. E.S.A. "Luiz de Queiroz", Universidade de São Paulo, Piracicaba, 1-92.

., 1958. Influência do clima sobre a fruta cítrica. IN : Curso Avançado de Citricultura. E.S.A. "Luiz de Queiroz", Universidade de São Paulo, Piracicaba, 33-35. São Paulo, 1-102. 
MONTENEGRO, H.W.S., 1973. Informe sobre a situação abacatícola. Relatório para a COPEME, São Paulo, 1-9 (mimeografado).

MORIN, C., 1965. El palto-clima. IN : Cultivo de Frutales Tropicales y Menores. Editorial Jurídica S/A, Lima, Peru, 63-65.

PANERAI, L., 1968. La coltura dll'avocado nel bacino del mediterraneo. Agric. Subtrop. e Tropic. Inst. Agron. Per L'Oltremare, Firenze, Itália, 299-325.

PAQUOT, C. \& TASSEL, H.M., 1966. Sur l'insaponifiable de l'huile d'avocat (Persea americana). Oleagineaux, 21(7):453-454.

PINTO H.S.; ORTOLANI, A.A.. \& ALFONSI, R.R., 1972. Estimativa das temperaturas médias mensais do Estado de São Paulo em função da altitude e latitude. Instituto de Geografia da USP, São Paulo, Cad. de Ciências da Terra, nọ 23, 1-20.

PRATT, H.K. \& BIALE, J.B., 1944. Relation of the production of an active emanation to respiration in the avocado fruit. Plant Physiology, 19519-528.

PRALORAN, J.C., 1970. Le climat des aires d'origine des avocatiers. Fruits. I.F.A.C., France, 25(7/8) $543-557$.

REUTHER W. \& RIOS-CASTAÑO, D., 1969. Comparison of growth, maturation and composition of citrus fruits in subtropical California, and tropical Colombia. Proc. First. Inter. Citrus Symp. University of California/Riverside, 1:277-300.

SADIR, R., 1972. Olio di abacate: tecnologia dell'estrazione e industrializzazione dei residui. La Rivista Italiana Delle Sostange Grasse, 49(2) 90-93.

SAMPAIO, V.R., 1974. Florescimento do abacateiro: épocas de ocorrência. Revista da Agricultura, Piracicaba, SP, 49(2/3):121-123.

SCHWOB, R., 1951. Composition chimique de l'avocat (Persea americana). Fruits. I.F.A.C., France, 6(5):177-183.

STAHL, A.L., 1933. Changes in composition of Florida avocados in relation to maturity. University of Florida. Agricultural Experiment Station Gainesville, Florida, U.S.A., Bull. 259, $1-61$.

TANGO, J.S.; COSTA, S.J. da; ANTUNES, A.J. \& FIGUEIREDO, I.B., 1969/70. Composição do fruto e do óleo de diferentes variedades de abacate cultivados no Estado de São Paulo. Coletânea do Instituto de Tecnologia de Alimentos, Campinas, SP, 3-283-292.

THIERS, H., 1971. L'huile d'avocat et son insapossifiable en cosmétologie et en thérapeutique dermatologique ou médicale. Fruits. I.F.A.C., France, 26:133-135.

TIJERO, R.F., 1964. Cultivo del palto. Servicio de Investigación y Promoción Agrária, Min. Agric. Lima, Peru. Bol. Téen., $52: 1-24$.

ULRICH, R., 1952. La vie des fruits. Masson et Cia. Editeurs. Paris, France, 1-370. 
